\title{
DOI: 10.21055/0370-1069-2020-1-103-108
}

УДК 614.8:615.371

\author{
Т.А. Костюкова, М.В. Гордеева, М.Н. Ляпин, К.М. Морозов
}

\section{НОРМАТИВНОЕ ОБЕСПЕЧЕНИЕ БИОЛОГИЧЕСКОЙ БЕЗОПАСНОСТИ ПРИ РАБОТЕ С МИКРООРГАНИЗМАМИ III-IV ГРУПП ПАТОГЕННОСТИ}

\author{
ФКУЗ «Российский научно-исследовательский противочумный институт «Микроб», Саратов, Российская Федерация
}

Цель исследования - анализ действующей нормативно-методической документации по вопросам безопасной работы с патогенными биологическими агентами (ПБА) III-IV групп патогенности. Материалы и методы. В работе использован аналитический метод. Проведен компаративный анализ положений действующих документов, утвержденных в разные сроки для разных ведомств, по вопросам оборудования систем очистки воздуха, использования боксов микробиологической безопасности, обеспечения лабораторий раковинами для мытья рук, проверки дезсредств, поступающих в лабораторию, и обеззараживания отходов. Результаты и обсуждение. В ходе анализа действующей документации рассмотрены положения, требующие доработки и уточнения в следующих изданиях санитарных правил. Большего внимания заслуживают два аспекта: проблема регламентирования устройства системы приточно-вытяжной вентиляции в лабораториях микробиологического профиля для работы с ПБА и проблема необходимости создания единой согласованной системы нормативной документации. Приведенные в статье примеры показывают необходимость соблюдения единого подхода к требованиям по обеспечению биобезопасности в документах различных ведомств, четких формулировок, согласованной системы нормативной и технической документации на лабораторное оборудование, определяющей основные характеристики боксов микробиологической безопасности и вентиляционных систем. Документы должны соответствовать требованиям различных ведомств. К обслуживанию инженерных систем должны привлекаться специалисты с соответствующим образованием на постоянной основе.

Ключевые слова: нормативная документация, биологическая безопасность, приточно-вытяжная вентиляция, фильтры тонкой очистки воздуха, боксы микробиологической безопасности.

Корреспондирующий автор: Костюкова Татьяна Алексеевна, e-mail: rusrapi@microbe.ru.

Для цитирования: Костюкова Т.А., Гордеева М.В., Ляпин М.Н., Морозов К.М. Нормативное обеспечение биологической безопасности при работе с микроорганизмами III-IV групп патогенности. Проблемы особо опасных инфекций. 2020; 1:103-108. DOI: 10.21055/0370-1069-2020-1-103-108

\section{T.A. Kostyukova, M.V. Gordeeva, M.N. Lyapin, K.M. Morozov}

\section{Regulatory Framework for Biological Safety Provision When Working with Microorganisms of the III-IV Pathogenicity Groups}

Russian Research Anti-Plague Institute "Microbe", Saratov, Russian Federation

Abstract. Objective of the study was to review the current normative-methodological documentation on the matters of safe handling of pathogenic biological agents (PBA) of the III-IV pathogenicity groups. Materials and methods. We used analytical method for the study. We carried out comparative analysis of the provisions contained in the current regulations approved at different times for different agencies on the matters of air filtering system equipping, usage of microbiological safety cabinets, ensuring hand washing station provision for laboratories, inspection of disinfectants entering a lab, and waste decontamination procedures. Results and discussion. We have considered the provisions of the current documentation that require further refinement and clarification for the future editions of sanitary regulations. Two aspects draw increasing attention: the problem of regulating the inlet and exhaust ventilation system setup in the laboratories of microbiological specialization for work with PBA and the need to devise a consistent coordinated regulatory framework. Examples provided in the paper demonstrate the necessity of adhering to the integrated unified approach to the requirements for biosafety provision in the documents of various agencies; clear wording; harmonized system of normative and technical specifications for laboratory equipment, stating the basic characteristics of microbiological safety cabinets and ventilation systems. The documents should be in compliance with the requirements of various agencies. The maintenance of technical-engineering systems should be performed by the specialists with an appropriate qualification on a regular basis.

Key words: normative documentation, biological safety, inlet and exhaust ventilation system, fine filters for air purification, microbiological safety cabinets.

Conflict of interest: The authors declare no conflict of interest.

Corresponding author: Tatiana A. Kostyukova, e-mail: rusrapi@microbe.ru.

Citation: Kostyukova T.A., Gordeeva M.V., Lyapin M.N., Morozov K.M. Regulatory Framework for Biological Safety Provision When Working with Microorganisms of the III-IV Pathogenicity Groups. Problemy Osobo Opasnykh Infektsii [Problems of Particularly Dangerous Infections]. 2020; 1:103-108. (In Russian). DOI: 10.21055/03701069-2020-1-103-108

Received 24.12.2018. Accepted 11.05.2019.

Проблема биологической безопасности сохраняет приоритетное значение при выполнении работ с возбудителями инфекционных заболеваний.
Требования биологической безопасности направлены на обеспечение защиты как персонала, проводящего исследования, так и населения, а также окру- 
жающей среды. Основные требования, касающиеся безопасных манипуляций с патогенными биологическими агентами (ПБА), определены санитарноэпидемиологическими правилами (СП) и санитарными правилами и нормами (СанПиН). Проведенный анализ действующей нормативной документации выявил ряд противоречий в требованиях по соблюдению биологической безопасности.

Целью настоящего исследования является анализ нормативной документации по вопросам обеспечения безопасности при работе с микроорганизмами III-IV групп патогенности, рассмотрение и сравнение требований и положений в действующих документах, утвержденных в разные сроки для разных ведомств.

\section{Материалы и методы}

В исследовании использовался аналитический метод. Проведен компаративный анализ положений действующих документов, утвержденных в разные сроки для разных ведомств, по вопросам оборудования систем очистки воздуха, использования боксов микробиологической безопасности (БМБ), обеспечения лабораторий раковинами для мытья рук, проверки дезсредств, поступающих в лабораторию, обеззараживания отходов.

\section{Результаты и обсуждение}

Приказом Роспотребнадзора от 02.02.2009 г. № 230 введен «Примерный регламент взаимодействия противочумных учреждений Роспотребнадзора с управлениями Роспотребнадзора по субъектам Российской Федерации и ФГУЗ «Центр гигиены и эпидемиологии» Роспотребнадзора в субъектах Российской Федерации по обеспечению санитарноэпидемиологического благополучия населения по опасным инфекционным болезням». Он гласит, что в основу взаимодействия положены «...единая госполитика в области обеспечения санитарноэпидемиологического благополучия, принципы единства и унификации методов диагностики, единства требований биологической безопасности...», согласование совместных мероприятий, а также информационное взаимодействие. Одним из пунктов предусмотрен контроль противоэпидемической готовности медицинских учреждений на случай возникновения очагов особо опасных инфекционных болезней. В соответствии с названным документом Управление Роспотребнадзора разрабатывает комплексные планы по обеспечению санохраны территории, проводит контроль противоэпидемической готовности учреждений здравоохранения к проведению первичных мероприятий и подготовке госпитальной базы при появлении больных или лиц с подозрением на заболевания, вызванные опасными возбудителями, а также проводит семинары для специалистов медучреждений по вопросам обеспечения биобезопасности.

В ходе исследования анализу подвергалось со- держание нормативных документов - санитарных правил по безопасности работ с ПБА, материалов периодической печати, электронных ресурсов. При этом сравнивались требования биобезопасности, представленные в документах и реализуемые на практике. Написание статьи инициировано материалами, полученными в ходе кураторских проверок региональных центров гигиены и эпидемиологии, клинических, а также ветеринарных лабораторий.

Можно выделить требования, которые в большей степени соблюдаются лабораториями: наличие лицензии, санитарно-эпидемиологического заключения, а, следовательно, обученного персонала, набора помещений, отвечающего выполняемой работе и обеспечивающего поточность движения инфицированного материала. Выполняются медикобиологические мероприятия (предварительные и периодические медосмотры, вакцинация и т.д.). Сложнее обстоит дело с инженерно-техническим оснащением, оборудованием и надлежащей его эксплуатацией.

В ряде случаев выполнение некоторых положений СП 1.3.2322-08 трудно оценить при проверке, так как в действующем документе, в отличие от СП 1.3.3118-13 «Безопасность работы с микроорганизмами I-II групп патогенности (опасности)», зачастую отсутствуют конкретные требования, например, не указано фильтры какого класса защиты должны быть установлены на входе и выходе вентиляционных приточно-вытяжных систем.

Основным документом, регламентирующим требования безопасной работы с микроорганизмами III-IV групп патогенности, являются санитарноэпидемиологические правила СП 1.3.2322-08 «Безопасность работы с микроорганизмами III-IV групп патогенности (опасности) и возбудителями паразитарных болезней». Санитарные правила устанавливают порядок проведения исследований в лабораторных условиях. Биологическая безопасность при проведении работ в медицинских учреждениях определена СанПиН 2.1.3.2630-10 «Санитарноэпидемиологические требования к организациям, осуществляющим медицинскую деятельность». Оба документа являются нормативными, оба составлены и введены Федеральной службой по надзору в сфере защиты прав потребителей и благополучия человека. Однако некоторые требования, особенно инженернотехническое обеспечение, прописаны недостаточно конкретно, что усложняет задачу специалистов, имеющих медицинское образование, правильно сориентироваться и составить техническое задание на проектирование, например, вентиляции с учетом предполагаемых задач, которые планируются выполнять в подразделении.

Проблемным для исполнения является и вопрос размещения раковин для мытья рук. В СП 1.3.2322-08 п. 2.3.29 однозначно указано, что раковины располагают в предбоксах или коридорах перед выходом из заразной зоны лаборатории. Данному положе- 
нию противоречит требование ГОСТ Р 52905-2007 «Лаборатории медицинские. Требования безопасности», раздел 6.2 которого гласит «Во всех рабочих зонах, где обрабатывают биологические материалы, должны быть установлены раковины для мытья рук...» и там же далее «Раковины для мытья рук, установленные в зонах, где обрабатывают биологические материалы, должны иметь беспрепятственный сток...».

Особое внимание должно уделяться обеззараживанию воздуха как в пределах рабочих зон микробиологических лабораторий, так и палат инфекционных больных. Воздушно-капельный механизм передачи возбудителя является самым опаснымпроисходит быстрое распространение инфекции. До 90 \% инфекционных заболеваний в мире составляют инфекции, передающиеся через вдыхаемый воздух [1]. Разработаны и используются различные способы обеззараживания воздуха: ультрафиолетовое облучение, фильтрация через фильтры высоких классов очистки воздуха, обеззараживание озоном, обработка помещений аэрозолями дезсредств, использование рециркуляторов, сочетающих в себе фильтры высокого класса очистки с ультрафиолетовым облучением [2-5].

СП 1.3.2322-08 - основной документ, определяющий требования биобезопасности микробиологических лабораторий, проводящих работу с ПБА ІІІIV групп, не регламентирует класс фильтров очистки воздуха, которые устанавливают на приточновытяжную систему вентиляции. Отсутствуют сведения о необходимости установки вентиляции в лабораториях, аттестованных для работы с патогенами IV группы. В зарубежных руководствах [6-8] для базовых лабораторий, отнесенных к 1 уровню биологической безопасности, отсутствуют требования наличия вентиляции или боксов микробиологической безопасности. Оснащение лабораторий 2 уровня биологической безопасности также возможно без использования микробиологических боксов, а система вентиляции рассматривается как желательное, но не обязательное оборудование. И только на 3 уровне лабораторий биологической безопасности обязательным становится как использование микробиологических боксов, так и приточно-вытяжной вентиляции. Таким образом, появляется основание для более детального анализа существующих нормативных документов и возможная их коррекция в национальных правилах, в частности для лабораторий, проводящих работу с микроорганизмами IV группы патогенности, включающей, помимо патогенных, и непатогенные микроорганизмы.

Аналогичные замечания нашли подтверждение в статье А.А. Ененко [9]. Автор обращает внимание на проблему отсутствия в СП 1.3.2322-08 необходимой информации по устройству приточно-вытяжной вентиляции. В статье приведены схемы монтажа вентиляции, указаны важные детали, на которые следует обратить внимание при проектировании, а затем при проверке защитной эффективности фильтров очистки воздуха. Показана необходимость герметичности воздуховодов, чтобы не произошло загрязнение помещений, в которых не ведется работа с ПБА, но через которые проходят воздуховоды.

Согласно СанПиН 2.1.3.2630-10 «Санитарноэпидемиологические требования к организациям, осуществляющим медицинскую деятельность» проектирование и эксплуатация приточно-вытяжной вентиляции должны отвечать следующим правилам: паспортизация приточно-вытяжной вентиляции; наличие ответственного лица в организации или из другой специализированной организации, осуществляющего эксплуатацию вентиляционной системы; ежегодная проверка защитной эффективности вентиляции; наличие на выходе фильтров класса H14. Эти требования согласуются с представленными в СП 1.3.3118-13 для лабораторий, проводящих работу с ПБА I-II групп.

Подобные сведения должны быть нормативно закреплены для лабораторий, выполняющих работу с использованием ПБА III-IV групп. Перечисленные выше требования, отсутствующие в СП 1.3.2322-08, должны найти адекватное степени опасности выполняемых исследований отражение в следующей редакции правил по соблюдению требований биологической безопасности при работе с материалом, содержащим ПБА III-IV групп патогенности.

Согласно СанПиН 2.1.3.2630-10 (п. 6.11) кроме системы вентиляции в медицинских учреждениях должно быть предусмотрено естественное проветривание помещений класса Б, к числу которых относятся помещения микробиологических лабораторий и палат для инфекционных больных (за исключением помещений чистоты класса А, например операционных). Независимо от «принятой системы вентиляции рекомендуется проветривание палат не менее 4 раз в сутки» (п. 6.40 СанПиН 2.1.3.2630-10). Последнее положение противоречит требованиям к вентиляционным системам, логично выставленным в других пунктах, а также требованиям п. 2.3.13 СП 1.3.2322-08 («Окна и двери помещений «заразной» зоны должны быть герметичными»).

Если под «естественной вентиляцией» следует понимать открывающиеся форточки или окно, то маловероятно, что через фильтр, стоящий в окне, будет осуществляться движение воздуха без механического побуждения. Как в таком случае должно выполняться требование п. 6.20 («В существующих зданиях, при отсутствии в инфекционных отделениях приточновытяжной вентиляции с механическим побуждением, должна быть оборудована естественная вентиляция с обязательным оснащением каждого бокса и боксированной палаты устройствами обеззараживания воздуха, обеспечивающими эффективность инактивации микроорганизмов не менее чем на $95 \%$ на выходе»)? Требование «естественной вентиляции» повторяется и в п. 6.40 СанПиНа 2.1.3.2630-10: «Независимо от принятой системы вентиляции реко- 
мендуется проветривание палат не менее 4 раз в сутки по 15 минут»). Очевидно, что приведенные требования не могут быть выполнены в силу абсолютного противоречия. В следующих выпусках документов должны найти отражение процедура и порядок проверки фильтров на защитную эффективность и их замены (предварительное и окончательное обеззараживание, защитная одежда для специалистов, выполняющих эту процедуру), создание направленности воздушного потока из чистых помещений в сторону заразных, где непосредственно проводятся манипуляции с ПБА.

В соответствии с разделом 14.2 ГОСТ Р 529052007 «Лаборатории медицинские. Требования безопасности» все пробы, культуры, отходы лабораторий следует рассматривать как потенциально содержащие ПБА. Работу с таким материалом согласно пункту 2.3.30 СП 1.3.2322-08 следует проводить с использованием боксов микробиологической безопасности, которые при правильной эксплуатации создают дополнительную защиту персонала и окружающей среды от воздействия микроорганизмов за счет создаваемого направленного потока воздуха и воздушной завесы в проеме бокса. В СП по безопасности работ с ПБА следует внести требования, определяющие взаимосвязь использования БМБ с определенными параметрами при том или ином уровне биологической опасности работ.

В работе А.А. Ененко [10] со ссылкой на ГОСТ Р ЕН 12469-2010 [Национальный Стандарт Российской Федерации ГОСТ Р ЕН 12469-2010 «Биотехнология. Технические требования к боксам микробиологической безопасности». Стандартинформ; 2010. 48 с.] даны характеристики БМБ, указано, что их эксплуатация предусматривает обязательное техническое обслуживание, периодические проверки рабочих характеристик - не только эффективности защиты фильтров, но и направленности и однородности нисходящего потока воздуха. В действующих на настоящий момент СП такие сведения не представлены. Этот же автор отмечает отсутствие единой согласованной системы нормативнотехнической документации, определяющей «минимум технических и эксплуатационных характеристики БМБ, а также регламентирующий порядок эксплуатации и проведения проверок» [11].

Наличие современного инженерно-технического защитного оборудования (приточно-вытяжной вентиляции, БМБ) и его эксплуатация требуют присутствия в организации надлежащего обслуживающего персонала (инженера или техника с соответствующим образованием и специальной подготовкой). Анализ требований п. 2.3.39 СП 1.3.3118-13 позволяет сделать вывод о том, что проверка защитной эффективности боксов микробиологической безопасности представляет собой проведение исследований (испытаний) по оценке соответствия эксплуатационных характеристик боксов требованиям Приложения 9 к СП 1.3.3118-13 «Боксы микро- биологической безопасности» (табл. 10.1, 10.2, 10.3) и ГОСТ Р ЕН 12469-2010 «Биотехнология. Технические требования к боксам микробиологической безопасности».

Согласно ГОСТ ISO/IEC 17000-2012 «Оценка соответствия. Словарь и общие принципы», объект оценки соответствия - это материал, продукция, система, процесс, установка, орган или лицо, к которым возможно применить оценочную деятельность.

Оценка соответствия включает в себя такие виды деятельности, определяемые в ГОСТ ISO/IEC 17000-2012 как испытание, контроль и сертификация, а также аккредитация органов по оценке соответствия.

Федеральным законом от 27.12.2002 г. № 184-Ф3 «О техническом регулировании», однозначно предусмотрен допуск к деятельности по подтверждению соответствия только аккредитованных лабораторий.

В силу требований Федерального закона от 28.12.2013 г. № 412-Ф3 «Об аккредитации в национальной системе аккредитации» юридические лица, индивидуальные предприниматели, выполняющие работы по оценке соответствия, подлежат аккредитации в национальной системе аккредитации.

Функции национального органа по аккредитации в Российской Федерации возложены на Федеральную службу по аккредитации (Росаккредитация).

Учитывая вышеизложенное, к проведению проверки защитной эффективности боксов микробиологической безопасности необходимо привлекать только организации, аккредитованные в Федеральной службе по аккредитации и имеющие соответствующую область аккредитации с составлением протоколов проверки установленного образца.

Для установки, проверки и обслуживания оборудования, в частности, систем приточно-вытяжной вентиляции и БМБ, должны привлекаться специалисты, имеющие соответствующее образование и государственную аккредитацию, что подтверждается Федеральным законом от 27.12.2002 г. № 184-Ф3 «О техническом регулировании», Федеральным законом от 28.12.2013 г. № 412-Ф3 «Об аккредитации в национальной системе аккредитации», ГОСТ Р ЕН 12469-2010 «Биотехнология. Технические требования к боксам микробиологической безопасности», ГОСТ ISO/IEC 17000-2012 «Оценка соответствия. Словарь и общие принципы».

Наряду с рассмотренными выше широко распространенными проблемами использования оборудования часто встречаются отступления от выполнения требований по применению дезинфицирующих средств.

Пункт 2.12.12 СП 1.3.2322-08 предусматривает контроль вновь поступающих партий дезсредств на содержание активного вещества. Далеко не всегда это требование выполняется из-за отсутствия в лаборатории специалиста химика или соответствующего оборудования. Потребители пользуются све- 
дениями, предоставленными производителем на момент выпуска продукции. Закупки осуществляют небольшими партиями, чтобы избежать длительного хранения. Но неизвестно, соблюдались ли требования транспортировки и хранения дезинфектантов, осталось ли содержание активного вещества на изначальном уровне. Не для всех дезинфицирующих средств есть официально выпускаемые (коммерческие) тест-полоски, которые позволили бы проводить определение концентрации активного вещества в рабочих растворах. Не во всех лабораториях выполняется П. 2.12.13 СП, касающийся наличия выделенных помещений для хранения запаса дезсредств и приготовления рабочих растворов. Выполнение требований по обращению с дезинфицирующими средствами не должно оставаться без внимания при проведении проверок лабораторий.

В лабораториях, проводящих диагностические исследования, осуществляется производственный контроль. Одним из элементов его является наличие СОП, детально прописанных и документально закрепленных методик, используемых для проведения каждого анализа, порядка выдачи результата и повторного проведения анализа в спорных случаях. В проверочных листах и на этапах аккредитации этот момент находит отражение. Поэтому вполне логично включить его и в санитарные правила по безопасной работе с микроорганизмами III-IV групп патогенности (опасности).

Все отходы микробиологических лабораторий являются потенциально инфицированными. Последовательность действий по их удалению направлена на уменьшение опасностей при сборе, транспортировке и вывозе с территории организации при минимальном вредном воздействии на окружающую среду.

В лечебных учреждениях отходы класса Б собирают на специально отведенных участках (блок централизованного обеззараживания медицинских отходов), где подвергают обеззараживанию, после этого вывозят на городской пункт утилизации отходов медицинских учреждений.

Правила обращения с отходами, в частности их удаление с территории организации, определяются договором на вывоз обеззараженных отходов на специальные полигоны медицинских отходов (в соответствии с требованиями СанПиН 2.1.7.2790-10 «Санитарно-эпидемиологические требования к обращению с медицинскими отходами»). После физических методов обеззараживания, приводящих к изменению внешнего вида отходов, допускается накапливание отходов класса Б и В, временное хранение и захоронение совместно с отходами класса А. В обязательном порядке на упаковке отходов классов Б и В должна быть отметка о прохождении обеззараживания.

Очистка и обеззараживание сточных вод от медицинских учреждений должны осуществляться на общегородских или других канализационных очистных сооружениях, гарантирующих эффективную очистку и обеззараживание сточных вод (регламентировано СанПиН 2.1.3.2630-10 п. 5.2). При отсутствии общегородских или других очистных сооружений сточные воды ЛПО должны подвергаться полной биологической очистке и обеззараживанию на локальных сооружениях. В последние годы в зависимости от профиля медицинского учреждения вводятся локальные очистные сооружения. В этом случае в общую канализационную сеть поступают обеззараженные стоки. Положения по обращению с медицинскими отходами или ссылки на действующие нормативные документы должны быть представлены и в новых редакциях санитарных правил.

Таким образом, в ходе анализа действующей документации рассмотрены положения, требующие доработки и уточнения в следующих изданиях санитарных правил. Большего внимания заслуживают два аспекта: проблема регламентирования устройства системы приточно-вытяжной вентиляции в лабораториях микробиологического профиля для работы с ПБА и проблема необходимости создания единой согласованной системы нормативной документации.

Приведенные в статье примеры показывают необходимость соблюдения единого подхода к требованиям по обеспечению биобезопасности в документах различных ведомств, четких формулировок, согласованной системы нормативной и технической документации на лабораторное оборудование, определяющей основные характеристики БМБ и вентиляционных систем. Документы должны соответствовать требованиям различных ведомств. К обслуживанию инженерных систем должны привлекаться специалисты с соответствующим образованием на постоянной основе.

Конфликт интересов. Авторы подтверждают отсутствие конфликта финансовых/нефинансовых интересов, связанных с написанием статьи.

\section{Список литературы}

1. Борисоглебская А.П. Лечебно-профилактические учреждения. Общие требования к проектированию систем отопления, вентиляции и кондиционирования воздуха. М.: «АВОК-ПРЕСС»; 2008. 144 c.

2. Борисоглебская А.П. Лечебно-профилактические учреждения: обеззараживание воздуха. АBOK: вентиляция, отопление, кондииионирование воздуха, теплоснабжение и строительная теплофизика. 2013; 3:30-3.

3. Наголкин А.В., Володина Е.В., Акимкин В.Г. Борисоглебская А.П., Сафатов А.С. Обеззараживание воздуха в медицинских организациях: тенденции развития Медицинский алфавит. 2015; 1(6):44-9.

4. Вассерман А.Л. Современная технология применения ультрафиолетового излучения для обеззараживания воздушной среды в помещениях ЛПУ. Поликлиника. 2016; (1-4):36-8.

5. Сисин Е.И. Сравниваем технологии обеззараживания воздуха в медицинских организациях. Санэпидконтроль. Охрана труда. 2016;2:75-84.

6 . Всемирная организация здравоохранения. Практическое руководство по биологической безопасности в лабораторных условиях. 3-е изд. Женева; 2004. 201 с.

$113 \mathrm{p}$

7. Laboratory Biosafety Guidelines, 3-rd ed. Canada; 2004.

8. Chosewood L.C., Wilson D.E., editors. Biosafety in Microbiological and Biomedical Laboratories. 5th ed. U.S. Department of Health and Human Services Public Health Service Centers for Disease Control. Prevention National Institutes of Health; 2009. 415 p. 
9. Ененко А.А. Проблемы эксплуатации и проверки систем приточно-вытяжной вентиляции в лабораториях, работающих с патогенными микроорганизмами III-IV групп патогенности. АВОК: вентиляция, отопление, кондиционирование воздуха, теплоснабжение и строительная теплофизика. 2016; 8:28-35.

10. Ененко А.А. Боксы биологической безопасности. Основы эксплуатации и обслуживания Клинико-лабораторный консилиум. 2012; 3:92-5.

11. Ененко А.А. Особенности проверки целостности НЕРА и ULPA фильтров в боксах микробиологической безопасности. Технология чистоты. 2014. 2:14-9.

\section{References}

1. Borisoglebskaya A.P. [Treatment and Prevention Facilities. General Requirements to Heating, Ventilation, Air Conditioning System Design]. M.: "AVOK-Press", 2008. 144 p.

2. Borisoglebskaya A.P. [Treatment and prevention facilities: air decontamination]. [AVOK: ventilation, heating, air conditioning, heat supply, and construction thermophysics7. 2013; 3:30-3.

3. NagolkinA.V., VolodinaE.V.,Akimkin V.G.,Borisoglebskaya A.P., Safatov A.S. [Air disinfection in medical organizations: development trends]. Meditsinsky Alfavit [Medical Alphabet]. 2015; 1(6):44-9.

4. Vasserman A.L. [Modern technology of ultraviolet radiation application for decontamination of indoor air in treatment and prevention facilities]. Poliklinika [Outpatient clinic]. 2016; (1-4):36-8. 5. Sisin E.I. [Comparing technologies for air decontamination in healthcare facilities]. Sanepid Kontrol'. Okhrana Truda [Sanitary Epidemiological Control. Occupational Safety]. 2016; 2:75-84.

6. World Health Organization. [Laboratory Biosafety Manual]. $3^{\text {rd }}$ edition. Geneva; 2004. $201 \mathrm{p}$.

$113 \mathrm{p}$.
8. Chosewood L.C., Wilson D.E., editors. Biosafety in Microbiological and Biomedical Laboratories. 5th ed. U.S. Department of Health and Human Services Public Health Service Centers for Disease Control. Prevention National Institutes of Health; 2009. $415 \mathrm{p}$

9. Enenko A.A. [Problems of exploitation and testing of balanced ventilation systems in the laboratories working with pathogenic microorganisms of the III-IV groups of pathogenicity]. [AVOK: ventilation, heating, air conditioning, heat supply, and construction thermophysics]. 2016; 8:28-35.

10. Enenko A.A. [Microbiological safety cabinets. Basic principles of operation and maintenance]. Kliniko-Laboratorny Konsilium [Clinical-Laboratory Consilium]. 2012; 3:92-5.

11. Enenko A.A. [Peculiarities of integrity check of HEPA and ULPA filters in microbiological safety cabinets] Tekhnologiya Chistoty [Technology of Cleanliness]. 2014. 2:14-9.

Authors:

Kostyukova T.A., Gordeeva M.V., Lyapin M.N., Morozov K.M. Russian Research Anti-Plague Institute "Microbe". 46, Universitetskaya St., Saratov, 410005, Russian Federation. E-mail: rusrapi@microbe.ru.

\section{Об авторах:}

Костюкова Т.А., Гордеева М.В., Ляпин М.Н., Морозов К.М.

Российский научно-исследовательский противочумный институт «Микроб». Российская Федерация, 410005, Саратов, ул. Университетская, 46. E-mail: rusrapi@microbe.ru.

Поступила 24.12.18.

Принята к публ. 11.05.19. 